\title{
OBSERVATION OF MEYER-NELDEL RULE FOR THE NON-ISOTHERMAL CRYSTALLIZATION OF GLASSY $\mathrm{Se}_{70} \mathrm{Te}_{30-x} \mathrm{Ag}_{x}$ ALLOYS
}

\author{
N. Mehta ${ }^{1}$, A. Kumar ${ }^{2}$ \\ ${ }^{1}$ Department of Physics, Pranveer Singh Institute of Technology, Kanpur, India, \\ ${ }^{2}$ Department of Physics, Harcourt Butler Technological Institute, Kanpur, India
}

(Received May 3, 2006; in final form - September 18, 2006)

\begin{abstract}
In the present paper, we report the observation of Meyer-Neldel rule for the non-isothermal crystallization of glassy $\mathrm{Se}_{70} \mathrm{Te}_{30-x} \mathrm{Ag}_{x}$ alloys. We have observed a strong co-relation between the pre-exponential factor $K_{0}$ of rate constant $K(T)$ of crystallization and activation energy of crystallization $E_{c}$ in the present case. This indicates the presence of compensation effect for the non-isothermal crystallization process in the present glassy system.

Key words: chalcogenide glasses, DSC technique, crystallization kinetics, activation energy of crystallization, arrhenius equation, Meyer-Neldel rule.
\end{abstract}

PACS number(s): 72.80.Ng, 61.43.Fs

\section{INTRODUCTION}

The Meyer-Neldel rule or MN rule (also known as compensation effect) is an empirical law known since 1937 [1]. This rule is observed in wide range of phenomena in physics, chemistry, biology and electronics [2-8]. It appears to be a fundamental property of many families of activated processes following an Arrhenius dependence on temperature:

$$
Y=Y_{0} \exp (-\Delta E / k T)
$$

Here $Y$ is the absolute rate of a thermally activated process, $Y_{0}$ the pre-exponential factor, $\Delta E$ the activation enthalpy and $k$ the Boltzmann constant. Commonly, by the evaluation of experimental data, the activation enthalpy is determined from the slope $(\Delta E / k)$ of an Arrhenius plot of $\ln Y$ vs $1 / T$. It is frequently found that, when $\Delta E$ is varied with a family of processes (for example, related chemical reaction), then pre-exponential factor $Y_{0}$ obeys the following empirical relation:

$$
Y_{0}=Y_{00} \exp \left(\Delta E / E_{\mathrm{MN}}\right)
$$

where $Y_{00}$ and $E_{\mathrm{MN}}$ are positive constants. $E_{\mathrm{MN}}$ is known as Meyer-Neldel energy for the process in question. Since then, the origin of this relation is referred to as the Meyer-Neldel relation or MN rule and the physical interpretation of $Y_{00}$ and $E_{\mathrm{MN}}$ has been the subject of speculations. The discussion of whether there is one universal explanation for the MN rule in different systems is not yet settled. Various plausible models have been proposed.

The hallmarks of the MN rule, linear behavior of the Arrhenius plot and a characteristic temperature where the compensation is exact, are often recognized. This rule is generally observed in disordered materials. In the class of amorphous semiconductors, the MN rule has been reported in a-Si:H films in which $\Delta E$ is varied by doping, by surface absorption, light soaking or by preparing films under different conditions [9-11].

In case of chalcogenide glasses also, $\mathrm{MN}$ rule is observed by the variation of activation energy $\Delta E$ of d.c. conduction on changing the composition of the glassy alloys [12-17] in a specific glassy system or by the variation of intensity of light $[18,19]$. In our laboratory also, different glassy systems were prepared by quenching technique and the observation of MN rule was reported in some of these glassy systems in a series of papers [12-14].

Though evidence of MN rule has been reported for a number of activated phenomena such as solid state diffusion in crystals and polymers, dielectric relaxation and conduction in polymers, thermally stimulated processes in polymers and electronic conduction in amorphous semiconductors [2-8], a less effort has been done to observe MN rule in kinetic phenomena such as crystallization phenomenon.

The crystallization phenomenon in chalcogenide glasses can be investigated using isothermal and nonisothermal methods. In isothermal method, the sample is brought near to crystallization temperature very quickly and then any physical quantity which changes drastically is measured as a function of time. In non-isothermal method, the sample is heated at a fixed rate and the physical parameter is recorded as a function of temperature. Any physical parameter, which changes drastically, can be taken as a measure of extent of crystallization as a function of time. A disadvantage of the isothermal method is the impossibility of reaching a test temperature instantaneously and during the time in which the system needs to stabilize, no measurements are possible. However, non-isothermal methods based on constant heating rate experiment do not have this drawback.

Recently, Ag based chalcogenide glasses have become attractive materials for fundamental research of their structure, properties and preparation [20-29]. They have many current and potential applications in optics and optoelectronics such as photo doping, optical imaging, photo lithography and phase change optical recording [20-29]. The low free energy of crystallization of $\mathrm{Ag}$ (48 kcal $/ \mathrm{mol}$.) was a further reason to consider the introduction of $\mathrm{Ag}$ in chalcogenide glasses used for phase change optical recording $[28,29]$. This enabled one for the attainment of the main requirements for good optical recording-high phase transformation rate. 
One other aspect of silver's influence in Ag-containing chalcogenide glasses is the effect on the electrical conductivity of the glasses, which can be changed by several orders of magnitude when Ag is introduced. Therefore, investigations on the influence of $\mathrm{Ag}$ on the physical properties of chalcogenide glasses are of relevance both from the basic science and application point of view.

In this paper, we have reported, the observation of $\mathrm{MN}$ rule for the crystallization of glassy $\mathrm{Se}_{70} \mathrm{Te}_{30-x} \mathrm{Ag}_{x}$ $(x=0,2,4,6)$ system. A strong correlation between the pre-exponential factor $K_{0}$ and activation energy of crystallization $E_{c}$ has been observed in the present study.

\section{MATERIAL PREPARATION}

Glassy alloys used in the present study were prepared by quenching technique. The exact proportions of high purity (99.999\%) elements, in accordance with their atomic percentages, were weighed using an electronic balance (LIBROR, AEG-120) with the least count of $10^{-4} \mathrm{gm}$. The material was then sealed in evacuated ( $\sim 10^{-5}$ Torr) quartz ampoules (length $\sim 5 \mathrm{~cm}$ and internal diameter $\sim 8 \mathrm{~mm})$. The ampoules containing material were heated to $1000^{\circ} \mathrm{C}$ and were held at that temperature for 12 hours. The temperature of the furnace was raised slowly at a rate of $3-4^{\circ} \mathrm{C} / \mathrm{min}$. During heating, the ampoules were constantly rocked, by rotating a ceramic rod to which the ampoules were tucked away in the furnace. This was done to obtain homogeneous glassy alloys.

After rocking for about 12 hours, the obtained melts were cooled rapidly by removing the ampoules from the furnace and dropping to ice-cooled water rapidly. The quenched samples were then taken out by breaking the quartz ampoules. The glassy nature of the alloys was ascertained by X-ray diffraction (XRD) technique. Absence of any sharp peak in XRD patterns of all the glassy alloys confirms the glassy nature of these alloys.

\section{EXPERIMENTAL}

The glasses, thus prepared, were ground to make fine powder for DSC studies. This technique is particularly important due to the fact that: (1) it is easy to carry out; (2) it requires little sample preparation; (3) it is quite sensitive and (4) it is relatively independent of the sample geometry.

The thermal behaviour was investigated using differential scanning calorimeter (Model-DSC plus, Rheometric Scientific Company, UK). The temperature precision of this equipment is $\pm 0.1 \mathrm{~K}$ with an average standard error of about $\pm 1 \mathrm{~K}$ in the measured values (glass transition and crystallization temperatures).

10 to $20 \mathrm{mg}$ of each sample was heated at a constant heating rate and the changes in heat flow with respect to an empty pan were measured. Four heating rates $(5$, 10,15 and $20^{\circ} \mathrm{C} / \mathrm{min}$ ) were chosen in the present study. Measurements were made under almost identical conditions. DSC scans of glassy $\mathrm{Se}_{70} \mathrm{Te}_{30-x} \mathrm{Ag}_{x}(x=0,2,4,6)$ system are shown in Fig. 1 at heating rate of $20 \mathrm{~K} / \mathrm{min}$. It is clear from these scans that well defined endothermic and exothermic peaks are observed at glass transition temperature $\left(T_{g}\right)$ and crystallization temperatures $\left(T_{c}\right)$ respectively. Similar DSC scans were obtained at other heating rates.
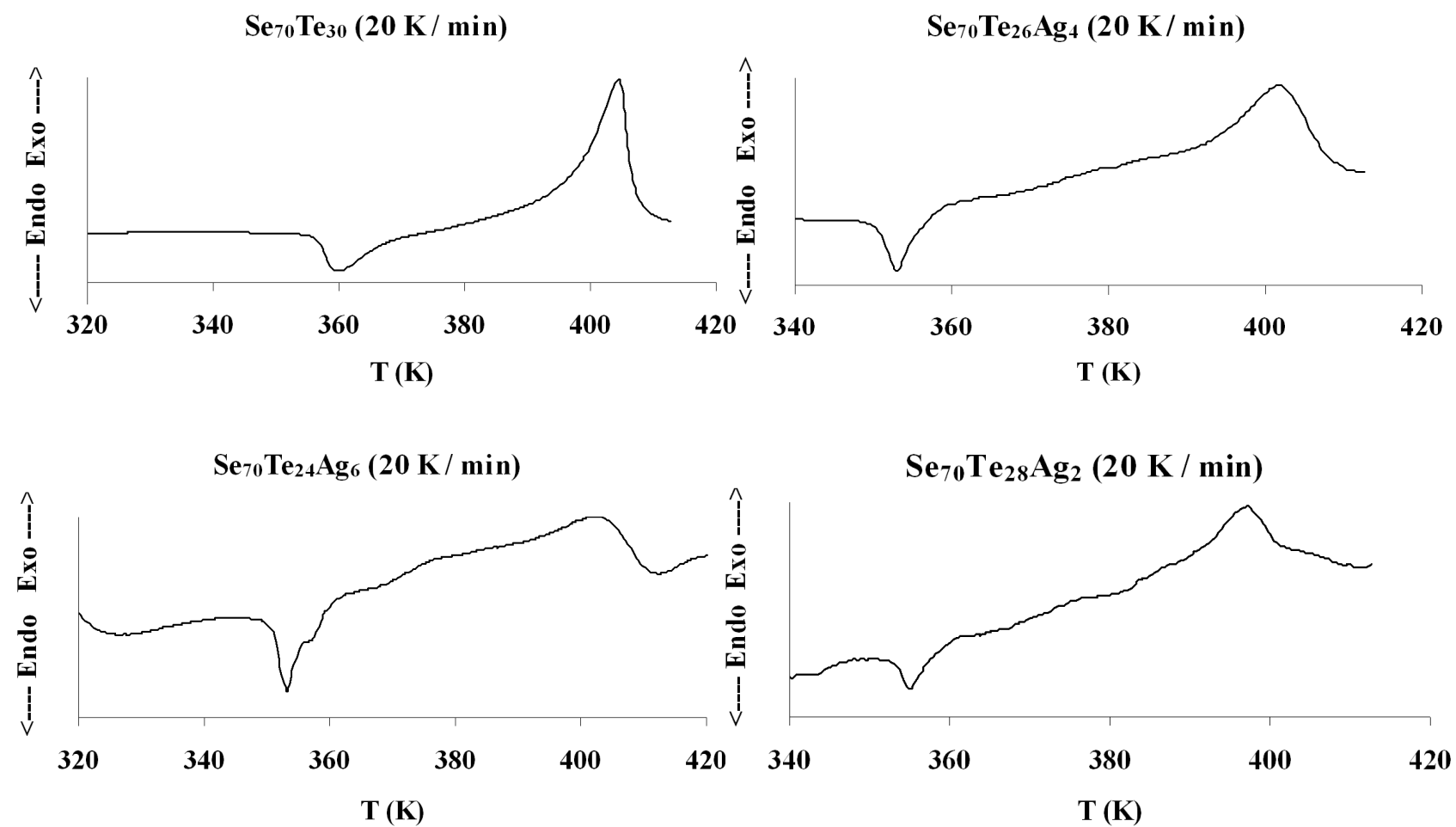

Fig. 1. DSC scans plots for glassy $\mathrm{Se}_{70} \mathrm{Te}_{30-x} \mathrm{Ag}_{x}$ alloys. 


\section{THEORETICAL BASIS}

During the isothermal transformation, the extent of crystallization $(\alpha)$ of a certain material is represented by the Avrami's equation [30-32]

$$
\alpha(t)=1-\exp \left(-K t^{n}\right),
$$

where $K$ is rate constant and $n$ is the order parameter which depends upon the mechanism of crystal growth.

In general, crystallization rate constant $K$ increases exponentially with temperature indicating that the crystallization is a thermally activated process. Mathematically, it can be expressed as:

$$
K=K_{0} \exp \left(-E_{c} / k T\right) .
$$

Where $E_{c}$ is the activation energy of crystallization, $K_{0}$ the pre-exponential factor and $k$ the Boltzmann constant. In equation (3), $E_{c}$ and $K_{0}$ are assumed to be practically independent of the temperature (at least in the temperature interval accessible in the calorimetric measurements).

In non-isothermal crystallization, it is assumed that there is a constant heating rate in the experiment. The relation between the sample temperature $T$ and the heating rate $\beta$ can be written in the form:

$$
T=T_{i}+\beta t,
$$

where $T_{i}$ is the initial temperature. The crystallization rate is obtained by taking the derivative of expression (3) with respect to time, bearing in mind that the reaction rate constant is a time function through its Arrhenius temperature dependence, resulting in:

$$
(d \alpha / d t)=n(K t)^{n-1}[K+(d K / d t) t](1-\alpha) .
$$

The derivative of $K$ with respect to time can be obtained from Eqs. (4) and (5) as follows:

$$
d K / d t=(d K / d T)(d T / d t)=\left(\beta E_{c} / R T^{2}\right) K .
$$

Then Eq. (6) becomes:

$$
(d \alpha / d t)=n K^{n} t^{n-1}[1+a t](1-\alpha),
$$

where $a=\left(\beta E_{c} / R T^{2}\right)$.

Augis and Bennett [33] developed a method based on Eq. (8). They taking proper account of the temperature dependence of the reaction rate, and their approach resulted in a linear relation between $\ln \left(T_{c}-T_{i}\right) / \beta$ versus $1 / T_{c}$. This can be deduced as follows, substituting $u$ for $K t$ into Eq. (8); the rate of reaction is expressed as:

$$
(d \alpha / d t)=n(d u / d t) u^{(n-1)}(1-\alpha)
$$

where

$$
(d u / d t)=u[(1 / t)+a]
$$

The second derivatives of Eqs. (9) and (10) are given by:

$$
\begin{aligned}
& \left(d^{2} \alpha / d t^{2}\right)=\left[\left(d u^{2} / d t^{2}\right) u-(d u / d t)^{2}\left(n u^{n}-n+1\right)\right] n u^{(n-2)}(1-\alpha)=0, \\
& \left(d u^{2} / d t^{2}\right)=(d u / d t)[(1 / t)+a]+u\left[\left(-1 / t^{2}\right)+(d a / d t)\right] .
\end{aligned}
$$

Recalling that $T=T_{i}+\beta t$ and substituting for $(d a / d t)=$ $-(2 \beta / T) a$, Eq. (12) can be written as:

$$
\left(d u^{2} / d t^{2}\right)=u\left[a^{2}+\left(2 a T_{i} / t T\right) .\right.
$$

The last term in the above equation was omitted in the original derivation of Augis and Bennett [33] $\left(T_{i} \ll T\right)$ and resulted in the simple form:

$$
\left(d u^{2} / d t^{2}\right)=a^{2} u
$$

Substitution of $(d u / d t)$ and $\left(d u^{2} / d t^{2}\right)$ from Eqs. (10) and (14), into Eq. (11) gives:

$$
\left(n u^{n}-n+1\right)=[a t /(1+a t)]^{2} .
$$

For $E / R T \gg 1$, the right-hand bracket approaches its maximum limit and consequently $u($ at the peak $)=1$, or

$$
u=(K t)_{c}=K_{0} \exp \left(-E_{c} / R T_{c}\right)\left[\left(T_{c}-T_{i}\right) / \beta\right] \approx 1 .
$$

In logarithm form, for $T_{i} \ll T_{c}$, we have

$$
\ln \left(\beta / T_{c}\right) \approx\left(-E_{c} / R T_{c}\right)+\ln K_{0}
$$

The values of $E_{c}$ and $K(T)$ can be evaluated by this equation using the plots of $\ln \beta / T_{c}$ against $1 / T_{c}$.

The above equation is derived by Augis and Bennett [33] from the classical JMA model [30-32]. Eq. (17) has been used by various workers [34-37]. Their results show that $E_{c}$ values obtained by equation (17) are in good agreement with the $E_{c}$ values obtained by well known Kissinger's relation [38] and relation of Matusita and Sakka [39, 40]. We have therefore used the method of Augis and Bennett [33, Eq. 17] to evaluate activation energy of crystallization $E_{c}$. This method has an extra advantage that the intercept of $\ln \beta / T_{c}$ vs $1 / T_{c}$ gives the value of pre-exponential factor $K_{0}$ of Arrhenius equation, which is in good agreement with the value that obtained directly from Arrhenius equation (Eq. (3)) using isothermal method [41, 42]. The values of $T_{c}$ for glassy $\mathrm{Se}_{70} \mathrm{Te}_{30-x} \mathrm{Ag}_{x}(x=0,2,4,6)$ system are given in Table 1 . 


\begin{tabular}{|l|c|c|c|c|}
\hline \multirow{2}{*}{ Sample } & \multicolumn{4}{|c|}{$T_{c}(K)$} \\
\cline { 2 - 5 } & $5 \mathrm{~K} / \mathrm{min}$ & $10 \mathrm{~K} / \mathrm{min}$ & $15 \mathrm{~K} / \mathrm{min}$ & $20 \mathrm{~K} / \mathrm{min}$ \\
\hline \hline $\mathrm{Se}_{70} \mathrm{Te}_{30}$ & 392.5 & 400.5 & 401.6 & 403.4 \\
\hline $\mathrm{Se}_{70} \mathrm{Te}_{28} \mathrm{Ag}_{2}$ & 386.8 & 390.0 & 395.2 & 396.5 \\
\hline $\mathrm{Se}_{70} \mathrm{Te}_{26} \mathrm{Ag}_{4}$ & 388.8 & 394.0 & 397.5 & 401.1 \\
\hline $\mathrm{Se}_{70} \mathrm{Te}_{24} \mathrm{Ag}_{6}$ & 389.0 & 395.6 & 399.1 & 401.4 \\
\hline
\end{tabular}

Table 1. Peak crystallization temperature $T_{c}$ of glassy $\operatorname{Se}_{70} \operatorname{Te}_{30-x} \operatorname{Ag}_{x}(x=0,2,4,6)$ alloys at different heating rates.

\begin{tabular}{|c|c|c|c|}
\hline Glassy system & $E_{c}$ & $K_{0}$ & $K_{0}=K_{00} \exp \left[E_{c} / k T_{0}\right]$ \\
\hline \hline $\mathrm{Se}_{70} \mathrm{Te}_{30-x} \mathrm{Ag}_{x}$ & $(\mathrm{eV})$ & $(\min )^{-1}$ & $(\min )^{-1}$ \\
\hline$x=0$ & 1.61 & $5.33 \times 10^{18}$ & $8.86 \times 10^{18}$ \\
\hline$x=2$ & 1.46 & $1.02 \times 10^{17}$ & $0.95 \times 10^{17}$ \\
\hline$x=4$ & 1.50 & $3.62 \times 10^{17}$ & $3.20 \times 10^{17}$ \\
\hline$x=6$ & 1.68 & $1.18 \times 10^{20}$ & $0.86 \times 10^{20}$ \\
\hline
\end{tabular}

Table 2. Values of $\mathrm{E}_{c}$ and $\mathrm{K}_{0}$ for glassy $\mathrm{Se}_{70} \mathrm{Te}_{30-x} \mathrm{Ag}_{x}(x=0,2,4,6)$ alloys.

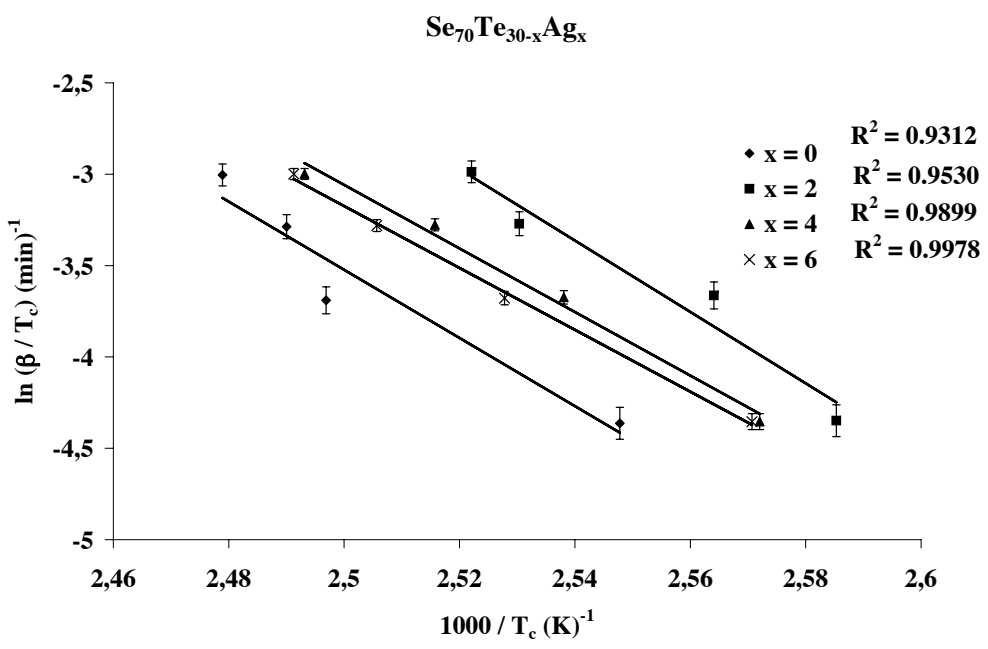

Fig. 2. $\ln \left(\beta / T_{c}\right)$ vs $10^{3} / \mathrm{T}_{c}$ plots for glassy $\mathrm{Se}_{70} \mathrm{Te}_{30-x} \mathrm{Ag}_{x}$ alloys.

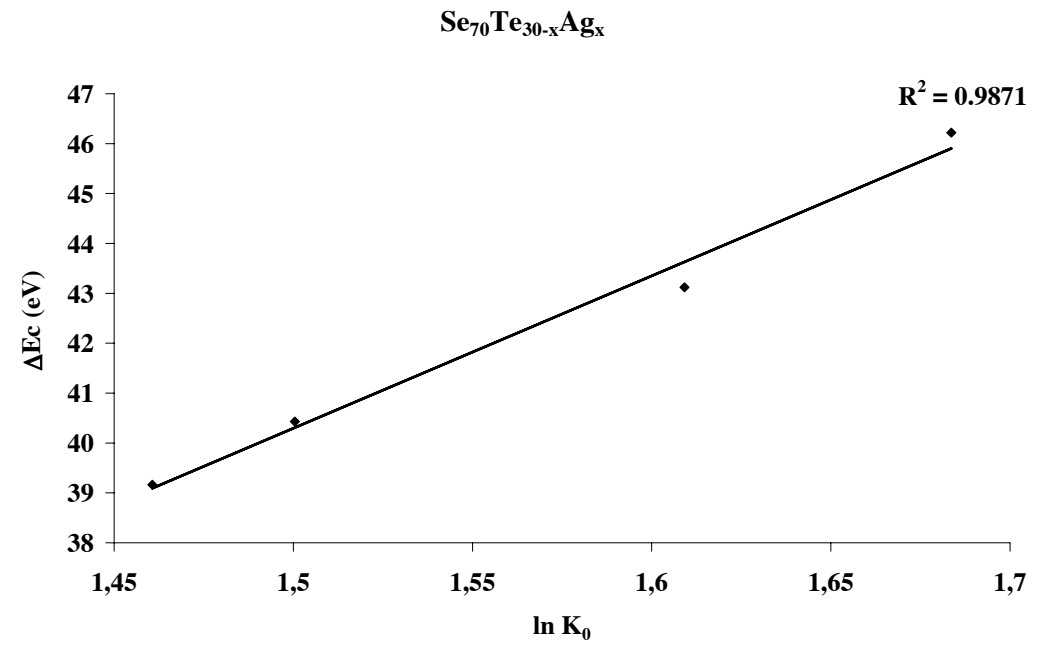

Fig. 3. Plot of $\ln K_{0}$ vs $E_{c}$ for glassy $\mathrm{Se}_{70} \mathrm{Te}_{30-x} \mathrm{Ag}_{x}$ alloys. 


\section{RESULTS AND DISCUSSION}

According to Eq. (17), the plot of $\ln \left(\beta / T_{c}\right)$ vs $10^{3} / T_{c}$ leads to a straight line. This has been verified for glassy $\mathrm{Se}_{70} \mathrm{Te}_{30-x} \mathrm{Ag}_{x}(x=0,2,4,6)$ system in Fig. 2. The activation energy of crystallization $E_{c}$ and pre-exponential factor $K_{0}$ of the glassy alloys have been calculated from the slopes and intercepts of the plots of $\ln \left(\beta / T_{c}\right)$ vs $10^{3} / T_{c}$. The values of $E_{c}$ and $\ln K_{0}$ for the present glassy system obtained from Eq. (17) are given in Table 2.

It is clear from this table that $E_{c}$ and $K_{0}$ are composition dependent and $K_{0}$ is not a constant but depends on $E_{c}$. Fig. 3 shows the plot of $\ln K_{0}$ vs $E_{c}$ for glassy $\mathrm{Se}_{70} \mathrm{Te}_{30-x} \mathrm{Ag}_{x} \quad(x=0,2,4,6)$ system. Curve fitting is done by least square method and the square of coefficient of correlation $\left(R^{2}\right)$ of $\ln K_{0}$ vs $E_{c}$ plot is indicated in the figure. It is clear from the figure that $\ln K_{0}$ vs $E_{c}$ plot is a straight line of good correlation coefficient indicating that $K_{0}$ varies exponentially with $E_{c}$ following the relation:

$$
\ln K_{0}=\ln K_{00}+E_{c} / k T_{0}
$$

From the slope and intercept of the line, we have calculated the values of $\left(k T_{0}\right)^{-1}$ and $K_{00}$. Using these values, the expected $\ln K_{0}$ values have been calculated for glassy $\mathrm{Se}_{70} \mathrm{Te}_{30-x} \mathrm{Ag}_{x} \quad(x=0,2,4,6)$ system and compared with the reported values (see Table 2). An overall good agreement between these two values confirms the validity of MN rule in glassy $\mathrm{Se}_{70} \mathrm{Te}_{30-x} \mathrm{Ag}_{x}(x=0,2,4,6)$ system.

Koga and Sestak [43] have shown that the kinetic compensation effect mathematically results from the expo- nential form of the rate constant. A change of activation energy is thus compensated by the same change in temperature or in the logarithm of the pre-exponential factor. In the present study also, the increase in $E_{c}$ is compensated by the increase in the pre-exponential factor $K_{0}$. However, it should be noted that the above observation is highly qualitative and it is difficult to get any quantitative information from such observation. Future experiments in this direction could reveal the exact origin for the observation of $\mathrm{MN}$ rule for non-isothermal crystallization of amorphous semiconductors such as we have observed for glassy $\mathrm{Se}_{70} \mathrm{Te}_{30-x} \mathrm{Ag}_{x}(x=0,2,4,6)$ system in the present study.

\section{CONCLUSIONS}

Glassy $\mathrm{Se}_{70} \mathrm{Te}_{30-x} \operatorname{Ag}_{x}(x=0,2,4,6)$ alloys have been prepared by quenching technique. Temperature dependence of crystallization rate constant $K(T)$ has been studied for various glassy alloys. We have find that $K(T)$ is thermally activated. The activation energy, however, depends on the composition.

The activation energy and pre-exponential factor satisfies the MN rule for present glassy system. This shows that the MN rule, which is generally observed for solid state diffusion in crystals and polymers, dielectric relaxation and conduction in polymers, thermally stimulated processes in polymers and electronic conduction in amorphous semiconductors; is also observed for the crystallization in chalcogenide glasses.
[1] W. Meyer, H. Neldel, Z. Tech. Phys. 18, 588 (1937).

[2] J. Deren, J. Haber, A. Podgorecka, J. Burzyk, J. Catalysis 2, 161 (1963).

[3] L. D. Ahuja, A. S. Brar, J. Colloid Interface Sci. 50, 197 (1975).

[4] T. Dosdale, R. J. Brook, Solid State Ionics 8, 297 (1983).

[5] R. Metselaar, G. Oversluizen, J. Sol. Stat. Chem. 55, 320 (1984).

[6] J. W. Niemantsverdriet, K. Markert, K. Wandelt, Appl. Surf. Sci., 31, 211 (1988).

[7] W. Bogusz, D. E. Kony, F. Krok, Mater. Sci. Eng. B 15, 169 (1992)

[8] G. C. Bond, Catalysis Today 49, 41 (1999).

[9] W. E. Spear, D. Allan, P. Lecomber, A. Gaith, Philos. Mag. B 41, 419 (1980).

[10] M. Tanielian, Philos. Mag. B 45, 435 (1982).

[11] R. S. Crandall, Phys. Rev. B 43, 4057 (1991).

[12] R. Arora, A. Kumar, Phys. Stat. Solidi A 1125, 273 (1991).

[13] S. K. Dwivedi, M. Dixit, A. Kumar, J. Mater. Sci. Lett. 17, 233 (1998).

[14] S. Singh, R. K. Shukla, A. Kumar, J. Non-Cryst. Solids 351, 1577 (2005).

[15] A. Abd-El Mongy, Egypt. J. Sol. 24, 207 (2001).

[16] Y. L. A. Ei-Kady, Physica B 305, 259 (2001).
[17] D. Kumar, S. Kumar, Bull. Mater. Sci. 27, 101 (2004).

[18] D. Kumar, S. Kumar, Vacuum 74, 113 (2004).

[19] D. Kumar, S. Kumar, J. Optoelectron. Adv. Mater. 6, 777 (2004).

[20] M. T. Kostyshin, E. V. Mikhailovskaya, P. F. Romanenko, Fiz. Tverd. Tela 8, 571 (1966).

[21] P. J. S. Ewen, A. Zakery, A. P. Firth, A. E. Owen, Philos. Mag. B 57, 1 (1988).

[22] A. V. Kolobo, S. R. Elliott, Adv. Phys. 40, 625 (1991).

[23] M. Mitkova, Z. Boncheva-Mladenova, J. Non-Cryst. Solids 90, 589 (1987).

[24] M. N. Kozickl, S. W. Hsia, A. E. Owen, P. J. S. Ewen, J. Non-Cryst. Solids 137-138, 1341 (1991).

[25] W. Leung, N. W. Cheung, A. R. Neureuther, Appl. Phys. Lett. 46, 481 (1985).

[26] T. Kawaguchi, S. Maruno, J. Appl. Phys. 77, 628 (1995).

[27] T. Kowaguchi, S. Maruno, S. R. Elliott, J. Non-Cryst. Solids 211, 187 (1997).

[28] N. Yoshida, M. Itioh, K. Tanaka, J. Non-Cryst. Solids 198-200, 749 (1996).

[29] N. Yamada, MRS Bull. 21, 48 (1996).

[30] W. A. Johnson, R. F. Mehl, Trans. Am. Inst. Min. Metall. Eng. 135, 416 (1939).

[31] M. Avrami, J. Phys. Chem. 7, 1103 (1939).

[32] M. Avrami J. Phys. Chem. 8, 212 (1940). 
[33] J. A. Augis, J. E. Bennett, J. Them. Anal. 13, 283 (1978).

[34] M. Abu El-Oyoun, J. Phys. D 33, 2211 (2000).

[35] A. Y. Abdel-Latif, Physica B 348, 348 (2002).

[36] A. A. Abu- Sehly, Physica B 325, 372 (2003).

[37] N. Mehta, M. Zulfequar, A. Kumar, J. Optoelectron. Adv. Mater. 6, 441 (2004).

[38] H. E. Kissinger, Anal. Chem. 29, 1702 (1957).
[39] K. Matusita, S. Sakka, Phys. Chem. Glasses 20, 81 (1979).

[40] K. Matusita, S. Sakka, Bull. Inst. Chem. Res. Kyoto Univ. 59, 159 (1981).

[41] P. Agarwal, Ph. D. thesis, Kanpur University (1991).

[42] A. Singh, Ph. D. thesis, Kanpur University (2000).

[43] N. Koga, J. Sestak, Thermochimica Acta 182, 201 (1991).

\title{
СПОСТЕРЕЖЕННЯ ПРАВИЛА МАЄРА-НЕЛЬДЕЛЯ ДЛЯ НЕІЗОТЕРМІЧНОЇ КРИСТАЛІЗАЦІї СКЛОПОДІБНИХ СПЛАВІВ $\mathrm{Se}_{70} \mathrm{Te}_{30-x} \mathrm{Ag}_{x}$
}

\author{
Н. Мегта ${ }^{1}$, А. Кумар ${ }^{2}$ \\ ${ }^{1}$ Технологічний інститут ім. П. Сінґ'ха, фізичний факультет, Канпур-208 002, Індія \\ ${ }^{2}$ Технологічний інститут ім. Г. Батлера, фізичний факультет, Канпур-208 002, Індія
}

У статті описано спостереження правила Маєра-Нельделя для неізотермічної кристалізації склоподібних сплавів $\mathrm{Se}_{70} \mathrm{Te}_{30-x} \mathrm{Ag}_{x}$. Виявлено сильну кореляцію між передекспонентним множником $K_{0}$ константи кристалізації $K(T)$ й енергією кристалізації $E_{c}$ у цьому випадку. Це засвідчує існування компенсаційного ефекту у процесі неізотермічної кристалізації досліджуваної склоподібної системи. 